\title{
Celebrity Gossip and the New Melodramatic Imagination
}

\author{
by David Beer and Ruth Penfold-Mounce \\ University of York
}

Sociological Research Online, Volume 14, Issue 2,

< http://wnw. socresonline.org.uk/14/2/2.htm/>

doi: $10.5153 /$ sro. 1878

Received: 8 Jan 2009 Accepted: 26 Apr 2009 Published: 30 Mar 2009

\begin{abstract}
This article uses a range of media sources to 'follow' or 'trace' the well-known celebrity Miley Cyrus. Through the development of the concept of a new melodramatic imagination the case study develops the methodological potentials of the types of online archives that now exist. In this instance the authors exercise their own melodramatic imaginations to draw out substantive issues relevant to the case of Miley Cyrus. The article therefore has two aims, the first is the exploration of a particular approach toward understanding transformations in popular culture, and the second is to draw out the types of 'grammar of conduct' that face those who assemble the information about celebrities into consumable narratives. The piece considers how people, in what has been called the Web 2.0 context, assemble melodramatic narratives amongst celebrity gossip that might then shape everyday experiences, understandings and practices.
\end{abstract}

\section{Keywords: Celebrity, Celebrity Gossip, Respectability, Miley Cyrus, Grammar of Conduct, Melodramatic Imagination}

'A minimal definition of gossip: "idle talk about other persons not present".' (Spacks, 1985:

26)

\section{Introduction}

1.1 Readers of this journal will no doubt be familiar with the rapidly expanding range of academic literature dealing with the topic of celebrity (see for example Feasey, 2008; Penfold-Mounce, 2009; Cashmore, 2006; Redmond and Holmes, 2007; Rojek, 2004; Ferris, 2007). This area of study - dealt with in varying ways by sociology, cultural studies, and media studies - has now also found its way onto undergraduate degree programmes as the interest in studying celebrity and fame have continued to increase amongst cohorts of students who are enthusiastic about bringing their interests into their studies (a sentiment that both authors can strongly associate with). The challenge, as things stand, is to find things to say about the matter of celebrity that goes beyond an enjoyment with re-counting the sensational narratives that constitute celebrities and the 'gossip' that shapes their perception. This is not to say that the literature on celebrity does not already do this, clearly there have been some valuable insights generated across a range of studies. Rather, in the first instance, what we are concerned with here is the weight of gossip that forms around particular celebrities as a result of what is a rapidly transforming mediascape (for an etymology of the word 'gossip' see Spacks, 1985: 25-26).

1.2 The fragmentation of media into an increasing variety of outlets is now beyond doubt, as is the increasing significance of contemporary developments in the web through which users are now much more active in creating, shaping and organizing media content. This changing mediascape is populated by multifarious media forms that enable gossip to circulate through channels that are both organisationally lead, such as the print and online versions of magazines and newspapers, and also now, due to the rise of what might be thought of as participatory web cultures, are a product of ordinary users participating in constructing web based content (Beer \& Burrows, 2007). The classic example here would be the now wellknown blog that is run by the celebrity gossip enthusiast Perez Hilton (who, ironically of course, has now become internationally famous as a result of the popularity of his blog). The circuits of celebrity gossip have become much denser. 
disseminated far beyond immediate friendship groups by consumers using the informational sources and dissemination potentials of the web. The point we would like to open with here is simply that not only do we have the difficulty of trying to understand celebrity culture, we also now face what we think is the more pressing problem of actually being able to get to grips with or stay on top of what is happening in celebrity culture as the information sources about it expand and diversify. Keeping up with and getting an understanding of celebrity culture, as a defining aspect of contemporary culture more generally, is now far more difficult as we consider the ubiquity, mobility and vastness of the information with which we are faced.

1.4 What we attempt to do in this article is immerse ourselves in this vast ocean of gossip by focusing upon and following one particular celebrity. The notion here is that objects or things, like celebrities, can be treated as mobile and contingent, rather than fixed and stable, and thus require approaches that can cope with and capture this mobility (Urry, 2007; Beer, 2008). This fits with a broader shift in sociology toward research practices that are concerned with making the most of new forms of data that are generated through everyday practices in the context of what Thrift describes as 'knowing capitalism' (Thrift, 2005; Savage \& Burrows, 2007 \& 2009) and with the general increase in interest in sociology with tracing and describing associations (Latour, 2005; De Landa, 2006), forms of emergence (Urry, 2003; Byrne, 2005) and the new sorting and tracking systems (Bowker \& Star, 1999; Lyon, 2007; Crang \& Graham, 2007). Amongst this literature we pick up in particular upon the type of methodological processes set out in the recent work of Scott Lash \& Celia Lury (2007) in which the authors follow a series of 'objects' of the 'global culture industry', in this case the object we have chosen to follow is the celebrity known as Miley Cyrus. The aim, in line with Lash and Lury's work, is to 'track the object as it moves and transforms through a media environment.' (Lash \& Lury, 2007: 31). The information that this 'following' of the object produces is intended to illustrate the type of narratives that are being constructed about celebrities, whilst also demonstrating how objects, such as a particular celebrity, can be followed or traced using contemporary media.

1.5 The digital traceability of cultural objects like celebrities enables new forms of investigation to be conducted into celebrity culture and popular culture more generally. In this instance we revisit the notion of a 'melodramatic imagination' (Ang, 1985) to begin to develop an approach toward and understanding of the ways that this plethora of information is now used to assemble narratives amongst the gossip. The article proposes that what we see within celebrity gossip is a version of what Helen Wood and Bev Skeggs, in reference to reality television, have described as a 'grammar of conduct' (Wood \& Skeggs, 2004). This piece attempts to track how this grammar of conduct emerges in complex and unpredictable ways as people exercise their new melodramatic imaginations amongst the plethora of information about celebrity life. The article begins with a discussion of the emergence of what might be thought of as a new melodramatic imagination. To then explore this point it focuses upon the celebrity figure Miley Cyrus before looking at how the gossip assembled around this celebrity figure forms a 'grammar of conduct' for its consumers. The piece concludes by revisiting the sociological significance of celebrity gossip and the traceability of cultural objects in light of this case study.

\section{The new 'melodramatic imagination'}

2.1 Before delving in to the specificities of our case study, it is worth beginning with a note intended to frame the context in which the study has been developed. To put this in conceptual terms we can revisit len Ang's (1985) influential application of Peter Brooks' (1976) concept of 'melodramatic imagination'. Brooks originally defined melodrama in the following terms:

'The connotations of the word...include: the indulgence of strong emotionalism; moral polarization and schematization; extreme states of being, situations, actions; overt villainy, persecution of the good, and final reward of virtue; inflated and extravagant expression; dark plottings, suspense,' (Brooks, 1976: 11-12; see also Mercer \& Shingler, 2004)

2.2 In Ang's (1985) reading, the melodramatic imagination is the consequence of a sensitivity on the part of the viewer to read the cultural text in a way that allows the above facets to be read-into the text and thus for the 'structure of feeling' to be appreciated. It works to enchant the everyday by finding the melodrama within cultural texts. The melodramatic imagination, in Ang's work, is about the psycho-social responses that are encouraged and cultivated through encounters with popular cultural texts, in this case the television show Dallas. Ang's contention is that the viewer uses the programme as a cultural resource from which they inform and stimulate an imaginative response. Thus the viewer is able to retreat from the monotony of the day-to-day into the stimulated melodrama.

2.3 In a key passage Ang says this:

'The melodramatic imagination should be regarded as a psychological strategy to overcome the material meaninglessness of everyday existence, in which routine and habit prevail in human relationships as much as elsewhere...The melodramatic imagination is therefore the 
expression of a refusal, or inability, to accept insignificant everyday life as banal and meaningless, and is born of a vague, inarticulate dissatisfaction with existence here and now.' (Ang, 1985: 79)

2.4 Clearly this is depicted by Ang as a process of temporary escape from the mundane and humdrum, a retreat initiated by an encounter with a cultural object that stimulates a re-enchantment of the everyday. Our suggestion is that we might now think through the possibility of the emergence of a new melodramatic imagination. It is important to note that when we use the prefix 'new' we do not necessarily mean that an entirely different conceptualisation of the melodramatic imagination to that offered by Brooks or Ang is required, rather what we mean is that the concept now needs to be regenerated to deal with a level of complexity that hitherto had not been the case. This then is to use the notion of a new melodramatic imagination to explore how these processes are being remediated by new media. The objective of overcoming the meaninglessness of the everyday, for instance, might remain unaltered, but, in a changing context, we can imagine the process of achieving this has changed. What has changed is the 'here and now' in which this process is occurring, that is to say that the content and media through which the melodramatic imagination is exercised has transformed in terms of its structure and its content. Where the cultural texts upon which the melodramatic imagination had been exercised had been limited in number, type and volume, now we are faced with a much greater range of cultural resources upon which to draw. The diversity of cultural texts available to the individual faced with broadening choices of media outlets including older media such as TV, radio and magazines, and newer media in the form of internet based and increasingly user led web applications such as Facebook, Youtube, Wikipedia and the plethora of blogs, is vast. The movement toward user-generated content, often referred to as Web 2.0 , is increasingly being considered a significant and telling transformation in the mediated social landscape - with people actively participating in creating (data) and sorting (metadata) media content (see for example Beer \& Burrows, 2007; Murthy, 2008). We do not then suggest here that Brooks and Ang's uses of the concept are wrong or even out of date, but rather that we now need to explore how the melodramatic imagination is operating in new ways in response to some key transformations in media and popular culture - with it now being applied in new ways, to new types of texts, in new types of cultural circuits, in new places, and so on. We imagine this as a part of a broader project that aims to regenerate some of the key concepts upon which we have relied but which were, of course, developed in a different historical context.

2.5 The melodramatic imagination now operates to locate the dramatic turns of narratives that are immersed in the almost incomprehensible scope of information available about things (a search on these now highly popular user led sites reveals that we can find out about virtually anything or anyone). The new melodramatic imagination operates to draw strands together and assemble 'structures of feeling' amongst this dirge of information. We can also add here a further observation, which is that in many cases, as we can see from the amount of blog postings, Youtube clips, and the like, that the melodramatic imagination is now exercised in circulating or even creating contributions that fill these vast archives of information about celebrities that are available on the web. The new melodramatic imagination then not only sensitively assembles the fragmented parts to interpret and understand the melodrama found in celebrity gossip, it is also active in shaping how these stories develop by participating in their dissemination for other melodramatic imaginations to encounter and interpret (beyond the immediate community to which gossip circulation was restricted in the past, see Harrington \& Bielby, 1995). We can see here how the new melodramatic imagination may not just be limited to the interpretation of texts but may also now be active and even mobile in assembling together the bits from a variety of texts across a mediascape in order to follow, appreciate and perpetuate the melodrama.

2.6 In many respects the approach we have adopted in the case study below is to exercise our own melodramatic (and sociological) imagination upon our object of study to see what it reveals to us about doing this kind of research, about the density of information that faces people in their everyday practices, and, finally, what this particular case study might tell us more generally about the substantive issues that are encountered by those interested in celebrity gossip. In constructing our case-study we tried to emulate these practices, our method was to search for our chosen celebrity figure in the way that those interested in this gossip might do so, searching and re-searching the name on Google, then using links to locate other related sites to get the sense of how the user might move through and encounter different types of content ${ }^{[1]}$. To use Bergmann's terminology, this is 'Gossip methodologically instrumentalized' (Bergmann, 1993: 5). Giving celebrity gossip this kind of treatment is particularly pressing when we consider that it is a preoccupation of a vast section of the social spectrum. For evidence of this popularity we can turn to the many celebrity dedicated television programmes, the substantial sales figures of celebrity gossip magazines like Heat and Closer, which both had audited weekly sales of over half a million copies in the UK in $2007{ }^{[2]}$, and the staggering amount of web sites of various forms dedicated to celebrity gossip. To take one specific example, the Perez Hilton blog (http://www.perezhilton.com) mentioned in the introduction to this article has, according to its author, received 228.7 million page views during the month of October 2008. The hope is that this approach will reveal something about how interested parties might go about 
exercising their melodramatic imaginations in the contemporary context and what they might find. We turn now to our object of study, Miley Cyrus.

\section{Miley Cyrus}

3.1 Born Destiny Hope Cyrus on $23^{\text {rd }}$ of November 1992 but otherwise known as Miley Cyrus, she is daughter of singer/actor Billy Ray Cyrus, of 'Achy breaky heart' fame, who nicknamed her 'Miley' as a baby because she was smiley[3]. She has since legally changed her name to Miley Ray Cyrus to 'honour' both her nickname and her father ${ }^{[4]}$. Cyrus is a teen singing and acting sensation in America for Disney, although she is not perhaps as well recognised by the general public in Britain (although this is changing quite rapidly). In fact when she was not mobbed by fans or paparazzi in London in October 2008 she admitted it was 'really strange' because 'No-one asked me for my autograph, no-one did anything, so I was like woah, this is really cool, this is really strange ${ }^{[5]}$. Cyrus's celebrity career began at age 12 when she auditioned for the best friend role in kid's television programme Hannah Montana for the Disney Channel but was eventually cast in the lead role when the show launched in March 2006. In the show Cyrus plays an ordinary school student, Miley Stewart, who is secretly also an international popstar known as 'Hannah Montana'. Following her casting in the show her father Billy Ray auditioned and was cast to play her father. As this article is being written Hannah Montana is entering its third season and is also to expand into cinema with Hannah Montana: the Movie due out in 2009.

3.2 Following the usual pattern, the popularity of the Hannah Montana series has led to a successful franchise for Disney with merchandise ranging from dolls, lunchboxes and electric guitars to digital cameras, home décor and even an inflatable bed ${ }^{[6]}$. It is not surprising that there is also a clothing collection inspired by the television show of which Cyrus helped to design some items. Donna Sheridan, vice president and general manager of apparel, footwear and accessories for Disney Consumer Products claimed that this range 'is not a costume. A tween girl isn't doing dress-up, they want to look like they could be Hannah Montana's friend.' Thus the clothes mimic Hannah's style by being 'sweet and appropriate for school with flashes of sparkle, ${ }^{\text {iil. }}$. Cyrus claimed that her aim is to 'look kind of like what girls would want to look up to, and their moms and dads will say, "Hey, that's cool. That's different",[7].

3.3 The success of the show led to the release of a Hannah Montana soundtrack CD with songs from the show in 2006. Cyrus also signed a four-album deal with Hollywood Records for her own albums. In June 2007, eight months after the first CD was released, Cyrus released a double album, Hannah Montana 2: Meet Miley Cyrus. The first disc was the second Hannah Montana soundtrack whilst the second disc was Cyrus's debut album of which, we are informed, she wrote eight of the ten songs. Just over a year later Cyrus released her second studio album, Breakout, which is the first release with no direct connection to Hannah Montana ${ }^{[8]}$. Cyrus has also enjoyed success on tour as both herself and in character as Hannah Montana. Her 'Best of Both Worlds' tour was extended due to demand leading to an additional 14 more dates than originally planned. The tour was recorded and released in just under a thousand cinemas in Disney Digital 3-D before being shown on the Disney Channel ${ }^{[9]}$.

3.4 Cyrus' meteoric ascent to stardom in less than five years has led to her being listed among artists and entertainers in Time magazine's 100 Most Influential People in the World in 2008 ${ }^{[10]}$ and immortalised in wax at Madame Tussauds in New York in the same year ${ }^{[11]}$. In addition she has written a book about her life and career. The Disney Book Group has bought the rights to publish the book with an anticipated release in spring 2009 ${ }^{[12]}$. However it is Cyrus's financial success that is most revealing of the scale of her stardom. In December 2007 Cyrus was listed in Forbes as one of the top twenty earners under the age of 25 annually earning $\$ 3.2$ million and ranked 35 on the 2008 Forbes Celebrity 100 with estimated earnings of $\$ 25$ million between June 2007 and June 2008. Some reports are projecting that Cyrus will be a billionaire by the time she turns $18^{[13]}$. However, the rhetoric is that despite this she remains grounded and ordinary with most of her wealth going into trust funds which she cannot touch until she is 18 , with a 'small' allowance paid in the meantime of $\$ 300$ a month ${ }^{[14]}$.

3.5 Cyrus's status has led to a range of opportunities opening to further her well-knowness (as it is sometimes referred to in celebrity discourse). She presented the song 'That's how you know' from the film Enchanted at the $80^{\text {th }}$ Academy Awards and has also hosted and performed at the 2008 CMT Music Awards, the American Idol fundraiser and Teen Choice Awards. Disney has also bolstered Cyrus's status by allowing her 'sweet sixteen' birthday party to be held at Disneyland seven weeks before her actual birthday. The pleasure park was shut for her party so that an estimated 5000 people who attended by buying $\$ 250$ tickets, were able to enjoy the rides along with a four-song performance by Cyrus and the inevitable fireworks display ${ }^{[15]}$. Cyrus's party also marked a public outing of her current relationship with 20 year-old underwear model, Justin Gaston. Illustrating the level of personal detail available to interested parties, we 
are able to find out that this relationship has been hailed by her father as a 'good thing' and that he is a 'good friend of the family' and a 'good kid'[16]. Gaston replaces her previous boyfriend Nick Jonas, from the well-known and internationally successful band, The Jonas Brothers, with who she was in a relationship for two years. Cyrus and Jones had managed to keep this relationship 'low key' and out of the public eye but her hit song ' 7 things' was rumoured to be based upon her relationship break up experience ${ }^{[17]}$.

3.6 What we find in the more recent coverage is that in addition to the personal details about her family, romantic relationships and her finances, controversy has also now begun to feature more prominently. Examples would include a mistaken pregnancy rumour ${ }^{[18]}$, her failure, along with her father, to wear seatbelts in a scene from Hannah Montana and Miley Cyrus: Best of Both Worlds Concert ${ }^{[19]}$, and complaints about concert tickets being overpriced or insufficient to meet demand ${ }^{[20]}$. However it is the emergence of photographic images of the teenager that has caused the most significant discussion. Despite becoming the youngest ever teenager to appear on the front cover of magazine Seventeen in September 2008 being considered an achievement by some ${ }^{[21]}$, other photographs have not been received with the same unambiguous support. First, candid images of Cyrus were leaked onto YouTube in which she displays some bra strap and midriff whilst draped over and cuddled up to a young male ${ }^{[22]}$. This challenged her previous images of either a glamorous lady in chic eveningwear at celebrity functions or as a teenage school girl in Hannah Montana.

3.7 This Youtube clip was followed a few days later by the Annie Leibovitz photographs for Vanity Fair [23]. The picture that caused the controversy was shot in Sepia showing Cyrus wrapped in a satin sheet, her bare back exposed with damp, tousled hair, her lips reddened and her eyes dark as she looks back over her shoulder. Although Cyrus said she thought the picture of herself was 'pretty and natural' and that it was 'really artsy' it has been widely contested. Germaine Greer - the well-known academic who is perhaps most famous amongst a non-academic audience for her appearance on Celebrity Big Brother - commented at the time that the picture was 'redolent of the dirty postcards of yesteryear'. ${ }^{24]}$ In line with our earlier arguments we can see with this issue how 'ordinary' web users are able to become involved in circulating (and even perpetuating or exacerbating) such controversies as one ex-fan wrote in his blog, 'She looked like she is freshly ${ }^{* * *}$ ked in these photos!' [25]. The Disney Channel also reacted in shocked manner releasing a statement saying that 'a situation was created to deliberately manipulate a 15 year-old in order to sell magazines' ${ }^{\prime 26]}$. The response to this was to point out that Cyrus's father and minders were on the shoot the whole day and, along with Miley, approved the shots ${ }^{[27]}$.

3.8 The controversy did not end there. Leibovitz in defence of her photograph of Miley expressed her disappointment in its misinterpretation asserting it to be 'a simple, classic portrait, shot with very little makeup and I think it is very beautiful' ${ }^{[28]}$. However despite the defence Cyrus in response to the internet circulation of the photo and media attention issued a statement of apology saying:

'I took part in a photo shoot that was supposed to be 'artistic' and now, seeing the photographs and reading the story, I feel so embarrassed. I never intended for any of this to happen and I apologize to my fans who I care so deeply about.' [29]

3.9 Cyrus has asked that her fans to 'understand that along the way I am going to make mistakes and I am not perfect'[30]. Cyrus withdrew from a red-carpet event at Disney World only days after the photographs were released but did participate in a session signing autographs for children at the resort ${ }^{[31]}$.

3.10 Cyrus has also been using user-led web applications to communicate with her fanbase. From February 2008, Cyrus and Mandy Jiroux (a backing dancer for Cyrus) have been co-creating and disseminating videos on YouTube called The Miley and Mandy Show. This show has become a popular download on Youtube (with one show achieving nearly 5 million views). It is filmed and edited together by Cyrus and Jiroux and is largely shot in Cyrus's bedroom. Cyrus and Jiroux have used the videos to show themselves dancing and having fun together whilst 'mugging' at the camera ${ }^{[32]}$. However they have also answered viewers' questions leading to the channel being dedicated to Jesus following their confirmation as Christians ${ }^{[33]}$; encouraged green living ${ }^{[34]}$ and taking viewers on Cyrus's private jet and her hotel room whilst on tour ${ }^{[35]}$. However the main focus of the YouTube videos is the two girls having fun via parody. In April 2008 The Miley and Mandy Show released a spoof of Madonna's '4 Minutes' video complete with backing dancers ${ }^{[36]}$. This use of parody then led to some criticism for mocking rival teen star Selena Gomez's clothes and teeth amid rumours that Gomez was dating Cyrus's ex-boyfriend Nick Jonas, Cyrus was 'super sorry' ${ }^{[37]}$ (for a discussion of Youtube and private lives on public display see Lange, 2007) 
videos which often use one of her songs playing over pictures and video clips, this includes videos with titles such as 'Nick Jonas and Miley Cyrus - Goodbye'[38]. With comments on this video posted by viewers ranging from 'aww i love that video!! its so sad! i totally think nick and miley should get back

together!!!!!!!!!!!' to 'this song makes me cry everytime because i just made the biggest mistake by breaking up with my boyfriend. i still love him so much and can really relate'. Cyrus's official music video's also invite comment although largely not about the actual video and song but rather about her and her behaviour. For example, another fan writes:

'This makes me so sick shes geeting all this puplicity from thosse 'pics' shes doing and little girls all look up to her beacause of her music and the jonas brothers shes wronged the in so maney ways i mean shes propperly put strain on nick [Nick Jonas] and selena [Selena Gomez]. [39]

3.12 The fan commentary and opinion on Cyrus is vast. Similarly footage and photographs of Cyrus doing the mundane are of apparent interest with innumerable photos, videos and the like. For example, we can watch videos of Cyrus on a rainy day going shopping with friends ${ }^{[40]}$. Fans even post photographs on fan blog sites such as http://mileycyrus.blogspot.com/ where images can be shared of Cyrus riding a bike, going out for meal or going to a tanning studio. Forums also debate Cyrus, often considering sensitive issues such as whether or not she has had sex. There are even entries on these forums claiming to have inside information on this issue ${ }^{[41]}$.

3.13 Providing us with a good illustrative example of the ongoing flow and changeability of celebrity gossip, whilst this paper was originally out for review further controversy occurred when Miley was captured in a photo with her friends making a 'slanted' eye gesture. This caused some widescale news coverage due to the inevitable interpretation as an offensive racial gesture. Cyrus's response was that they were simply pulling faces, however this has now escalated with the possibility of a lawsuit against Cyrus being reported by Fox News ${ }^{[42]}$.

3.14 Clearly, even in the process of filtering down the vast information with which we were faced in compiling this account of Miley Cyrus, we have still been left with a somewhat complex personal life story (imagine even attempting to stay on top of all the forum, blog and other gossip and opinion being posted about this one celebrity). We made the decision to limit this story for the purpose of the scope of this article, we could comfortably have continued to write further convolutes into the narrative. Indeed, a whole book length project would not have provided the space necessary to include all of the detail of just this one celebrity. This complexity of celebrity gossip, and the range of strands that could be pulled upon and developed, is clear to see simply by searching for some of these popular characters on Google. We see in the results of any such search both the range of topics that come up in the discussions about Cyrus and the number of possibilities for pursuing different narratives about her (and thus constructing a different version of the celebrity).

\section{A 'grammar of conduct'?}

4.1 The first thing to say is that we should not be surprised by the types of narratives we find in celebrity gossip. As Patricia Meyer Sparks observed in the mid 1980s:

'one might say that blatant sexual activity has become essential to certain public roles. Entertainers, for instance, rock stars and movie stars, use their sex lives, or a fantasized version of them, as part of their glamorous self-projection. Correspondingly, the activity of gossip, suppressed by official morality, flourishes in specified contexts: magazines, television.' (Spacks, 1985: 25)

4.2 Clearly though this was in response to an emergent aspect of popular culture the scale of which at that time could not have been predicted. Nor could the now common involvement of consumers in circulating and creating gossip for global dissemination have been factored in. Cyrus' story clearly resonates with the types of celebrity narratives that have been around for quite some time now, what is different is the mediascape in which these stories are told and circulated.

4.3 In considering Cyrus a useful starting point is the recent work of Bev Skeggs and colleagues on the social implications of reality television (see Skeggs, 2005; Wood \& Skeggs, 2008; Wood \& Skeggs, 2004; Skeggs \& Wood, 2008; Skeggs et al, 2008). We can imagine reality TV as an allied area of cultural 'trash' (Wood \& Skeggs, 2008) that parallels the types of resources we have used here in our discussion of Cyrus. As such we can also imagine, drawing upon the arguments forwarded by Wood and Skeggs, that the content of this celebrity gossip has equally far reaching consequences as it contributes toward the 'spectacular morality' (Wood \& Skeggs, 2008) of contemporary popular culture. Indeed, in many ways the 
content of reality television, as a 'spectacular' telling of the everyday, is reflected in the content of celebrity gossip, which also often tells of the mundane lives of celebrities in spectacular and moralising tones. It is notable that these areas often crossover in the hybrid form of celebrity reality $\mathrm{TV}$, with the proliferating reality shows which feature celebrities opening up their homes to film crews (including programmes like The Osbournes and Katie \& Peter amongst many others) or appearing in shows where they are expected to learn to dance (Strictly Come Dancing and Dancing with the Stars), figure skate (Dancing on Ice), cook (Celebrity Hell's Kitchen and Celebrity Come Dine With Me), be air crew (Celebair), fall in love (Celebrity Love Island and Age of Love), survive in the Australian Bush (I'm a Celebrity Get Me Out of Here ), and so on. Cyrus' Youtube video shows would also be a good example here of how this type of programming is now also becoming user led as celebrities try to communicate with audiences via online video repositories or, as they are referred to in web discourse, folksonomies. In the case of the more general media coverage of celebrity life we again find that images and (often self told) stories about everyday mundane routines are featured heavily (pictures with shopping bags in the street, biographical accounts of childhood, detailed descriptions of dietary and exercise routines, personal relationship issues, and the like). We can group all of these things within what Zygmunt Bauman (2007) has recently referred to as the 'confessional society' in which individuals feel obligated to reveal things about themselves. Or, as Brooks put it, the 'desire to express all seems a fundamental characteristic of the melodramatic mode. Nothing is spared because nothing is left unsaid.' (Brooks, 1976: 4). When we place the types of details we have found in the case of Cyrus alongside the work on reality television mentioned above it seems safe to conclude that we are seeing an increase in the interest in and consumption of everyday life (see Bauman, 2007; Beer \& Burrows, 2007). To take this further, a celebration of the drama in the ordinary. Miley Cyrus' Youtube shows are just one illustrative example of this, as are the pictures and tales depicting the ordinary and routine parts of her life.

4.4 A compelling argument made by Wood and Skeggs is that reality programming offers what they refer to as a 'grammar of conduct' (Wood \& Skeggs, 2004: 206). The contention here is that the narratives found in these shows influence directly understandings of class and gender differences in particular by providing a framework of otherness upon which viewers are able to draw. In particular they argue that these shows perpetuate or even 'make' class divisions through depictions of morality and respectability, or more often, according to the authors, a lack of these on the part of the white working-class characters featured in these shows (Skeggs, 2005; Wood \& Skeggs, 2008; Wood \& Skeggs, 2004; Skeggs \& Wood, 2008). Thus the authors claim that reality TV shows contribute to the cultural concretisation of social hierarchies by dividing those featured along the lines of respectability. As Skeggs has put it, it is the 'process of evaluation, moral attribution and authorization in the production of subjectivity that...is central to understanding contemporary class relations.' (Skeggs, 2005: 976). The argument here with regard to the social and cultural significance of reality television is clear; depictions of respectability attached to particular people are implicit in the formation of social relations and divisions. Similarly it is not too much of a stretch to apply this notion to celebrity gossip to suggest that within these forms of information we find, in the constructed stories assembled through the melodramatic imagination, a grammar of conduct emerging which will inevitably affect those who consume these sources. The implications of these are yet to be understood or even acknowledged. In the case of Cyrus it is clear that a spectacular morality and the attached grammar of conduct have formed around the interpretation and discussion of the Vanity Fair photographic images of her in bedclothes at the age of 15 , the detailed accounts of her relationships with her also famous pop-star boyfriends, the offensive 'slanted' eye photographs, and her reported abstinence communicated through her purity ring. These provide nodes within the assembled narratives around Cyrus and together are part of a constellation of spectacular moral tropes within which those assembling celebrity gossip narratives are able to locate a heterogeneous grammar of conduct.

4.5 The gossip about Cyrus shows strong themes of morality and respectability, particularly within the depictions of her more recent conduct. We can focus in particular here upon the tensions that occur with regard to the issue of respectability and purity. Cyrus's image and subsequent fame is based upon being a clean-living performer who often talks about her Christian faith. She is the ideal type Disney kid. She is known like other teen stars such as singer/actresses Selina Gomez, Demi Lovato ${ }^{[44]}$, Victoria Secrets model, Adriana Lima ${ }^{45]}$, to wear the now high-profile 'purity ring', a symbol of abstinence. However, as we have seen the Cyrus' purity has come under question from a range of sources following the controversy about the Vanity Fair photographs. This is indicative of a tension of respectability in the accounts of Cyrus, this is a tension formed between the pure and impure, often with the polarization of emotional and extravagant perspectives that we might expect from a melodrama. The tension is built as a range of contributors to the debate discuss the private issues of Cyrus life in an open and accessible public domain.

4.6 This case study suggests that we cannot think of media depictions of celebrities and the 'spectacular morality' (Wood \& Skeggs, 2008) we find within celebrity gossip, as being predominantly the domain of what used to be referred to as the mass media, rather now we need an approach that accounts for the involvement of web users as they comment on, append and even create new gossip (this of course would 
include things like footage taken on mobile phones). In the story of Cyrus, as in the melodramatic literary texts discussed by Brooks, we find 'a vision of the social world as the scene of dramatic choice between heightened moral alternatives' (Brooks, 1976: 5). The comments we have found on the personal life and activities of Cyrus on blogs and forums show that the melodramatic imagination is working in new ways that is not only about active forms of interpretation, but is also now manifesting itself within acts of cultural production. The consequence is that the types of grammars of conduct that Skeggs \& Wood pointed toward in their work are not only open to multiple interpretations they are also the product of the involvement of a range of types of participants drawing upon a range of types of sources. This reworking of the circuits of celebrity gossip is part of a much broader redrawing of the lines between cultural production and consumption that is now occurring (Beer \& Burrows, 2007; Ritzer, 2007). The result is that the constitution of a grammar of conduct follows a much more unpredictable pattern of emergence than in the past (Urry, 2003).

\section{Conclusion}

5.1 The sociological significance of celebrity gossip is, to our mind, far reaching and largely overlooked. It could even be said that celebrity gossip, and celebrity culture more generally, is perhaps the defining aspect of contemporary popular culture. Clearly we cannot unpick all of the dimensions of this sociological significance in this article, but we hope that we have opened some of these issues up for analysis. Because of the dominance of celebrity gossip in contemporary popular culture it is highly possible that something as seemingly banal as accounts of the dietary practices of celebrity figures could have far reaching consequences that we are yet to appreciate. These consequences might well be about what people eat, how they understand food and food preparation, and so on, but could also relate more closely than we might at first imagine to social divisions, social conduct and the formation of new cultural hierarchies. This is important if we accept that celebrity gossip not only tells stories about contemporary culture but also constitutes it and shapes its formation (see Skeggs, 2005: 976).

5.2 Tracking or following celebrities seems to now be a popular form of entertainment as individual agents consume and even create and circulate celebrity gossip. This new melodramatic imagination is built upon the assemblage (and circulation) of narratives constructed through the informational resources that face anyone operating in the contemporary informatised social landscape. The type of research we have attempted here, immersing ourselves in the information about a celebrity, does have its inevitable pitfalls. Which strands to follow? Where to begin? Which sources to use and how? The list goes on. However, our experiences suggest that the main difficulty is not the picking out of the narrative from the plethora of information and sources, rather the problem is how to deal with the density of information in the first place. What we are able to generate through the type of following the celebrity approach we have adopted here is an opening up of a 'grammar of conduct' (Wood \& Skeggs, 2005) that is being formed as celebrity gossip is circulated. The question that this article leaves open is how to engage analytically with the complex and mobile grammars of conduct of the new melodramatic imagination.

5.3 Ang's work on the TV show Dallas was written at a time when the broadcast model dominated, this was when the few chose the programmes or articles which were broadcast to the many (Poster, 1996). The broadcast model still dominates in some media sectors, but we also have to consider now how Ang's 'melodramatic imagination' might operate in the fragmented, participatory and decentralised mediascape of today as people go about assembling narratives out of vast sources of information, as they get involved in circulating or even creating this information, and as they face such overwhelming sources from which to construct the stories that populate, enchant and shape their everyday lives. Our suggestion is for a reworking of some of the concepts upon which we have relied, such as the melodramatic imagination, for the changes that are now emerging, particularly in relation to the involvement of users in generating online content. It is necessary now to consider how concepts like that of Ang's melodramatic imagination need to be rethought and regenerated given the transformation of culture and the mediascape over the last few years, in particular we point here toward the part of user participation in the dissemination of information about popular cultural forms.

5.4 Our suggestion at this juncture is that the new melodramatic imagination is a product of the part that the consumer is now playing in assembling media content. The new melodramatic imagination, we contend, now exercises itself and becomes embodied in the form of informational assemblages that are waiting to be interrogated, data-mined, and hopefully, understood. What this article suggests is a pressing need to adapt a conceptual vocabulary and research techniques that might cope with and account for the changes we have highlighted. Not least, in order to understand contemporary popular culture we now need to acquire practices that afford an engagement with the complex and often unpredictable forms of emergence (Urry, 2003) of something like celebrity gossip and the grammar of conduct that it offers. One possibility will be to not only study but also to exercise our own melodramatic imaginations in order to follow and assemble the emergent gossip that surrounds celebrity figures (which we see as being a crucial and prominent part of 
contemporary popular culture). This approach will inevitably force the sociology of popular culture to intersect with wider debates in the discipline around our analytical futures, the possibilities of the new information sources of the web, and the foregrounding of description over causality.

\section{References}

ANG, I. (1985) Watching Dallas: Soap opera and the melodramatic imagination. London \& New York: Routledge.

BAUMAN, Z. (2007) Consuming Life. Cambridge: Polity.

BEER, D. (2008) 'Making friends with Jarvis Cocker: Music culture in the context of Web 2.0', Cultural Sociology, vol. 2, no. 2, pp. 222-241.

BEER, D. \& Burrows, R. (2007) 'Sociology and, of and in Web 2.0: Some initial considerations', Sociological Research Online 12(5): <http://www.socresonline.org.uk/12/5/17.html>

BERGMANN, J.R. (1993) Discreet Indiscretions: The Social Organization of Gossip . New York: Aldine De Gruyter.

BOWKER, G.C. \& Star, S.L. (1999) Sorting things out: classification and its consequences . Cambridge, Massachusetts: The MIT Press.

BROOKS, P. (1976) The Melodramatic Imagination: Balzac, Henry James, melodrama, and the mode of excess. New Haven: Yale University Press.

BYRNE, D. (2005) 'Complexity, Configurations and Cases', Theory, Culture \& Society 22(5): 95-111.

CASHMORE, E. (2006) Celebrity/Culture, Abingdon, Oxon: Sage.

CRANG, M. \& Graham, S. (2007) Sentient cities: ambient intelligence and the politics of urban space. Information, Communication \& Society, 10, 6, pp. 789-817.

DELANDA, M. (2006) A New Philosophy of Society: Assemblage Theory and Social Complexity . London \& New York: Continuum.

FEASEY, R. (2008) 'Reading heat: The meanings and pleasures of star fashions and celebrity gossip', Continuum: Journal of Media \& Cultural Studies 22(5): 687-699.

FERRIS, K.O. (2007) 'The Sociology of Celebrity', Sociology Compass 1(1): 371-384.

HARRINGTON, C.L. \& Bielby, D.D. (1995) 'Where did you here that? Technology and the Social Organization of Gossip', The Sociological Quarterly 36(3): 607-628.

LANGE, P. (2007) 'Publicly Private and Privately Public: Social Networking on YouTube', Journal of Computer-Mediated Communication 13(1): 361-380.

LASH, S. and Lury, C. (2007) Global Culture Industry: the mediation of things , Cambridge: Polity Press.

LATOUR, B. (2005) Reassembling the Social: An Introduction to Actor-Network Theory. Oxford: Oxford University Press.

LYON, D. (2007) Surveillance Studies: An Overview. Cambridge: Polity.

MERCER, J. \& Shingler, M. (2004) Melodrama: Genre, Style, Sensibility. London \& New York: Wallflower. MURTHY, D. (2008) 'Digital Ethnography: An Examination of the Use of New Technologies for Social Research', Sociology 42(5): 837-855.

PENFOLD-MOUNCE, R. (2009) Celebrity Culture \& Crime. Basingstoke: Palgrave MacMillan

POSTER, M. (1996) The Second Media Age. Cambridge: Polity.

REDMOND, S. and Holmes, S. (eds.) (2007) Stardom and Celebrity: A Reader, London: Sage.

RITZER, G. (2007) 'Theorizing Web 2.0', presented at Toward a Social Science of Web 2.0, NSLC, York, 56 September. 
ROJEK, C. (2004) Celebrity, London: Reaktion.

SAVAGE, M. \& Burrows, R. (2007) 'The Coming Crisis of Empirical Sociology', Sociology 41(5): 885-900.

SAVAGE, M. \& Burrows, R. (2009) 'Some Further Reflections on the Coming Crisis of Empirical

Sociology', Sociology, forthcoming.

SPACKS, P.M. (1985) Gossip. New York: Alfred A. Knopf.

SKEGGS, B. (2005) 'The Making of Class and Gender through Visualizing Moral Subject Formation', Sociology 39(5): 965-982.

SKEGGS, B., Thumin, N. \& Wood, H. (2008) ' 'Oh goodness, I am watching reality TV' How methods make class in audience research', European Journal of Cultural Studies 11(1): 5-24.

SKEGGS, B. \& Wood, H. (2008) 'The labour of transformation and the circuits of value 'around' reality television', Continuum: Journal of Media \& Cultural Studies 22(4): 559-572.

THRIFT, N. (2005) Knowing Capitalism. London: Sage.

URRY, J. (2003) Global Complexity. Cambridge: Polity.

URRY, J. (2007) Mobilities. Cambridge: Polity.

WOOD, H. \& Skeggs, B. (2004) 'Notes on ethical scenarios of self on British reality TV', Feminist Media Studies, 4(1): 205-208.

WOOD, H. \& Skeggs, B. (2008) 'Spectacular Morality: 'Reality' Television, Individualisation and the Remaking of the Working Class', pp. 177-193 in D. Hesmondhalgh \& J. Toynbee (eds) Media and Social Theory. London: Taylor and Francis.

\section{Notes}

${ }^{1}$ This may appear in places to take the form of a 'sample of convenience'. Indeed, in some senses it is, at least in so far as in following the celebrity gossip we are attempting to emulate 'ordinary' user's practices as they find out about celebrities. These 'ordinary' users inevitably operate with a sample of convenience as they accumulate and find out things about the celebrities they are interested in. This is the practice we are trying to engage with. What we have tried to do here though is construct a story with a linear narrative whilst at the same time trying to record things as we discovered them. This of course creates some tension between the capturing and tracing of the object as information flows are encountered and negotiated on one hand, and trying to construct a readable narrative that can be followed and which is appropriate to the medium of an academic article on the other. This case study represents an attempt to work with this tension and to construct something that has some logic and coherence out of a complex plethora of detail available about the chosen celebrity. The work done behind the scenes for the article was, like the sources we were drawing upon, far less structured and linear, but required us to search repeatedly, follow links and encounter different types of sources to see what we could find out. The case study you see here is this mass of encountered information condensed and organised into a more structured narrative account of what we regarded as the most important, representative and significant information.

2 http://www.emap.com/press-office-item.asp?Resource=2845[accessed on 3/11/08]

${ }^{3}$ Miley Cyrus [accessed on 15/10/08]

http://en.wikipedia.org/wiki/Miley_Cyrus

${ }^{4}$ Miley Cyrus Makes Name Change Official, 29/1/2008 [accessed on 15/10/08]

http://www.people.com/people/article/0, 20174585,00.html

${ }^{5}$ The pop dream of teen queen Miley, 14/10/2008 [accessed on 15/10/08]

http://news.bbc.co.uk/1/hi/entertainment/7667260.stm

6 The pop dream of teen queen Miley, 14/10/2008 [accessed on 15/10/08]

http://news.bbc.co.uk/1/hi/entertainment/7667260.stm

7 Disney Targets Tween Shoppers, 20/6/2007 [accessed on 8/10/2008] 
8 Miley Cyrus: Being a Role Model Starts with the Clothes, 20/12/2007, [accessed on 9/10/2008] http://www.people.com/people/article/0,,20167543,00.html

${ }^{9}$ Miley Cyrus

http://en.wikipedia.org/wiki/Miley_Cyrus\#cite_note-post-25 [accessed 8/10/2008]

10 Miley Cyrus

http://en.wikipedia.org/wiki/Miley_Cyrus\#cite_note-post-25[accessed 8/10/2008]

11 http://www.time.com/time/specials/2007/article/0,28804,1733748_1733752_1734628,00.html[accessed on $8 / 10 / 2008]$

12 Wax Miley Cyrus Hits Madam Tussauds, 20/3/2007 [accessed on 8/10/2008]

http://www.people.com/people/article/0,,20185542,00.html

${ }^{13}$ Miley Cyrus Signs Seven Figure Book Deal, 22/4/2008 [accessed on 8/10/2008]

http://www.people.com/people/article/0,,20194112,00.html

US star Cyrus writes memoir at 15, 14/10/2008 [accessed on 15/10/2008]

http://news.bbc.co.uk/1/hi/entertainment/7668140.stm

14 Miley Cyrus to be billionaire, 5/5/2008 [accessed on 8/10/2008]

http://www.digitalspy.co.uk/showbiz/a95256/miley-cyrus-to-be-a-billionaire.html

${ }^{15}$ Miley Cyrus Fun Facts, [accessed on 9/10/2008]

http://www.people.com/people/miley_cyrus

16 Miley Cyrus celebrates Sweet 16 at Disneyland, 7/10/2008 [accessed on 8/10/2008] http://news.yahoo.com/s/ap/20081006/ap_en_mu/people_miley_cyrus

17 Billy Ray Cyrus Calls Miley's Boyfriend 'A Good Kid', 7/10/2008 [accessed on 8/10/2008] http://www.people.com/people/article/0, 20231559,00.html

18 Miley's ' 7 Things' is About Nick Jonas, says Director, 2/9/2008 [accessed on 15/10/2008] http://www.people.com/people/article/0,,20222798,00.html?xid=rss-topheadlines

19 Miley Cyrus Pregnancy Rumor is 'Completely Untrue', 24/9/2007 [accessed on 8/10/2008] http://www.people.com/people/article/0,,20058394,00.html

20 Billy Ray Cyrus Says He, Miley Just Forgot to Buckle Up, 13/2/2008 [accessed on 8/10/2008] http://www.foxnews.com/story/0,2933,330634,00.html

21 Miley Cyrus's Bittersweet Sixteen, 6/10/2008 [accessed on 8/10/2008] http://voices.washingtonpost.com/celebritology/2008/10/miley_cyruss_bittersweet_sixte.html

$22 \mathrm{http} / / / \mathrm{www}$. seventeen.com/magazine/cover-scene/miley-cyrus-cg-0908 [accessed on 8/10/2008]

23 Miley Cyrus Bra Flashing Pictures Hit Web [accessed on 8/10/2008]

http://www.huffingtonpost.com/2008/04/21/miley-cyrus-bra-flashing_n_97866.html

${ }^{24}$ Miley Knows Best, June 2008 [accessed on 8/10/2008]

http://www.vanityfair.com/culture/features/2008/06/miley200806

25 We like our Venuses young, 30/4/2008 [accessed on 8/10/2008]

http://www.guardian.co.uk/artanddesign/2008/apr/30/photography.women

${ }^{26}$ We like our Venuses young, 30/4/2008 [accessed on 8/10/2008]

http://www.guardian.co.uk/artanddesign/2008/apr/30/photography.women

27 Miley Cyrus Vanity Fair photo 'beautiful': Leibovitz, 28/4/2008 [accessed on 8/10/2008] http://www.cbc.ca/arts/media/story/2008/04/28/cyrus-photos-vanityfair.html?ref=rss 
${ }^{28}$ Leibovitz Defends Provocative Miley Cyrus Photos, 28/4/2008 [accessed on 9/10/2008] http://abcnews.go.com/entertainment/story?id=4736358\&page $=1$

29 Leibovitz Defends Provocative Miley Cyrus Photos, 28/4/2008 [accessed on 8/10/2008] http://abcnews.go.com/entertainment/story?id=4736358\&page $=1$

${ }^{30}$ Revealing Photo Threatens a Major Disney Franchise, 28/4/2008 [accessed on 8/10/2008] http://www.nytimes.com/2008/04/28/business/media/28hannah.html?

_r=1\&scp=1\&sq=Miley\%20Cyrus \%20Vanity\%20Fair\%20\&st=cse\&oref=slogin

31 Miley Cyrus Vanity Fair photo 'beautiful': Leibovitz, 28/4/2008 [accessed on 8/10/2008] http://www.cbc.ca/arts/media/story/2008/04/28/cyrus-photos-vanityfair.html?ref=rss

32 Cyrus pulls out of Disney's party, 2/5/2008 [accessed on 14/10/2008] http://news.bbc.co.uk/1/hi/entertainment/7379431.stm

33 Miley Cyrus Debuts YouTube Show, Dances to Janet, 26/2/2008 [accessed on 10/10/2008] http://www.people.com/people/article/0,,20180478,00.html

34 Miley Cyrus Dedicates Web Video to Jesus, 24/3/2008 [accessed on 10/10/2008] http://www.people.com/people/article/0,,20186041,00.html

35 Miley Cyrus Uses YouTube to Encourage Green Living, 19/8/2008 [accessed on 10/10/2008] http://www.greendaily.com/2008/08/19/miley-cyrus-uses-youtube-to-encourage-green-living/

36 Miley Cyrus Takes YouTube Viewers onto Her Private Jet, 10/3/2008 [accessed on 10/10/2008] http://www.people.com/people/article/0,,20183266,00.html

37 Miley Cyrus and Pal Mandy Spoof Madonna, 14/4/2008[accessed on 10/10/2008] http://www.people.com/people/article/0,,20191229,00.html

${ }^{38}$ Miley Cyrus Mocks Selena Gomez on YouTube, 25/7/2008 [accessed on 10/10/2008] http://www.huffingtonpost.com/2008/07/25/miley-cyrus-mocks-selena_n_115072.html Miley Cyrus Sorry for Mocking Selena Gomez on YouTube Video, 28/7/2008 [accessed on 10/10/2008] http://www.foxnews.com/story/0,2933,392042,00.html

$39 \mathrm{http} / / /$ uk.youtube.com/watch?v=ZqIQlqMaOZk [accessed on 15/10/2008]

40 http://uk.youtube.com/watch?v=HroWv5DJhuk [accessed on 15/10/2008]

${ }^{41}$ http://uk.youtube.com/watch?v=|3sLj5qhN-E [accessed on 15/10/2008]

42 http://www.topix.com/forum/who/miley-cyrus [accessed on 15/10/2008]

43 http://www.foxnews.com/story/0,2933,491304,00.html [accessed on 7/03/2009]

44 Seventeen, Sept 2008, p198

45 Purity: Why It's Never Been More Popular, 19/5/2008 [accessed on 10/10/2008] http://www.huffingtonpost.com/2008/05/19/purity-has-never-been-mor_n_102431.html?page=4 